\title{
BEZ235 impairs gastric cancer growth by inhibition of PI3K/mTOR in vitro and in vivo
}

\author{
Thorsten Füreder ${ }^{1}$, Thomas Wanek ${ }^{2}$, Pamina Pflegerl ${ }^{3}$, Agnes Jaeger-Lansky ${ }^{1}$, Doris Hoeflmayer ${ }^{1}$, Sabine Strommer ${ }^{1}$, \\ Claudia Kuntner ${ }^{2}$, Markus Müller ${ }^{1}$, Oliver Langer ${ }^{1,2}$, Volker Wacheck $^{1 *}$ \\ From 16th Scientific Symposium of the Austrian Pharmacological Society (APHAR) \\ Vienna, Austria. 25-27 November 2010
}

\section{Background}

Gastric cancer at advanced stage of disease is a major health problem and the prognosis with the current therapeutic treatment strategies remains poor. PI3K/mTOR pathway mutations, especially PTEN, PI3K3C and AKT mutations and pS6 overexpression, are found frequently in gastric cancer patients and are linked with poor outcome. Thus, we evaluated the dual PI3K and mTOR inhibitor BEZ235 against gastric cancer in vitro and in vivo.

\section{Materials and methods}

Three gastric cancer cell lines (N87, MKN28 and MKN45) were treated with BEZ235 (20-80 nM) and assessed for cell viability, cell death and cell cycle distribution. PI3K/mTOR protein target modulation was measured by Western blotting. For in vivo studies athymic nude mice were inoculated with N87 or MKN45 cells bilaterally and treated daily with 20 or $40 \mathrm{mg} / \mathrm{kg}$ BEZ235. Tumor $\left[{ }^{18} \mathrm{~F}\right]$ fluorothymidine (FLT) uptake was measured via small animal PET.

\section{Results}

In vitro, treatment of gastric cancer cells with $20-80 \mathrm{nM}$ BEZ235 decreased cell growth in a dose-dependent manner in all cell lines tested (up to $-70 \%$ ). This antiproliferative activity was linked with a $G_{1}$ cell cycle arrest (up to 75\%). No significant induction of apoptosis by BEZ235 was observed. On the molecular level, BEZ235 led to a decrease of phosphorylation of AKT and S6 protein. In vivo, treatment with 20 and $40 \mathrm{mg} / \mathrm{kg}$ BEZ235 resulted in a significant anti-tumor effect in a
N87 gastric cancer xenograft mouse model. BEZ235 therapy had no anti-tumort effect on MKN45 xenografts despite similar potent PI3K/mTOR target inhibition by BEZ235 in both xenograft models. However, expression of the proliferation marker thymidinthymidine kinase 1 correlated with sensitivity to BEZ235 in vivo. In line, $\left[{ }^{18} \mathrm{~F}\right] \mathrm{FLT}$ uptake was significantly reduced only in the BEZ235-sensitive tumor xenograft model as measured by small animal PET.

\section{Conclusions}

In conclusion, our study shows that dual PI3K/mTOR inhibition by BEZ235 is a valuable target for gastric cancer therapy but is tumor model-dependent. Correlative studies with implementation of non-invasive imaging tools such as $\left[{ }^{18} \mathrm{~F}\right] \mathrm{FLT}$ PET might be a novel and promising strategy for optimizing clinical testing of dual PI3K/mTOR inhibitors.

\section{Author details \\ ${ }^{1}$ Department of Clinical Pharmacology, Medical University of Vienna, 1090 Vienna, Austria. ${ }^{2}$ Health and Environment Department, Molecular Medicine, AlT Austrian Institute of Technology GmbH, 2444 Seibersdorf, Austria. ${ }^{3}$ Department of Pathology, Medical University of Vienna, 1090 Vienna, Austria.}

Published: 16 November 2010

doi:10.1186/1471-2210-10-S1-A41

Cite this article as: Füreder et al:: BEZ235 impairs gastric cancer growth by inhibition of PI3K/mTOR in vitro and in vivo. BMC Pharmacology 2010 10(Suppl 1):A41.

\footnotetext{
* Correspondence: volker.wacheck@meduniwien.ac.at

'Department of Clinical Pharmacology, Medical University of Vienna, 1090

Vienna, Austria

Full list of author information is available at the end of the article
} 